\title{
Recovery of left ventricular function after surgical correction of mitral regurgitation caused by leaflet prolapse
}

\author{
Rakesh M. Suri, MD, DPhil, ${ }^{\text {a }}$ Hartzell V. Schaff, MD, ${ }^{\mathrm{a}}$ Joseph A. Dearani, MD, ${ }^{\mathrm{a}}$ Thoralf M. Sundt, MD, ${ }^{\mathrm{a}}$ Richard C. Daly, MD, ${ }^{\mathrm{a}}$ \\ Charles J. Mullany, MB, MS, ${ }^{a}$ Maurice Enriquez-Sarano, MD, ${ }^{\mathrm{b}}$ and Thomas A. Orszulak, MD ${ }^{\mathrm{a}}$
}

Objective: Recovery of ventricular function after surgical correction of mitral regurgitation is often incomplete. We studied clinical and echocardiographic factors influencing return of normal left ventricular ejection fraction after mitral valve repair or replacement for mitral regurgitation caused by leaflet prolapse.

\begin{abstract}
Methods: We evaluated 1063 patients who had mitral valve repair or replacement between January 1, 1980, and December 31, 2000. A total of 2488 echocardiograms with follow-up ejection fractions were available for analysis.

Results: Of the patients, 761 were men, 924 had valve repair, and $85 \%$ underwent surgery during the study's second decade. Compared with patients who had the operation in the 1980 s, patients who had surgery in the 1990s had significantly smaller preoperative left heart dimensions and a 2.4-fold greater likelihood of an ejection fraction more than $60 \%$ during follow-up. Factors independently associated with higher ejection fraction at follow-up included valve repair (vs replacement), freedom from preoperative myocardial infarction, operation in the 1990s, greater preoperative ejection fraction, and smaller left ventricular dimensions. Patients with an ejection fraction of less than $50 \%$ at discharge were 3.5 -fold less likely to recover normal ejection fraction during long-term follow-up $(P<.001)$. Patients had a greater likelihood of a follow-up ejection fraction more than $60 \%$ if preoperative ejection fraction was more than $65 \%$ (hazard ratio, 1.7) or left ventricular end-systolic dimension was less than $36 \mathrm{~mm}$ (hazard ratio, 2.0).
\end{abstract}

Conclusion: Early repair of mitral regurgitation caused by leaflet prolapse, before deterioration in left heart size or function, increases the likelihood of subsequent normalization of left ventricular ejection fraction.

Significant mitral regurgitation (MR) leads to progressive deterioration in left ventricular (LV) function with time, ${ }^{1,2}$ but the extent to which LV function recovers after correction of MR is unclear. ${ }^{1}$ Furthermore, there is controversy on whether ejection fraction $(\mathrm{EF})$ recovers more completely after mitral valve (MV) repair or replacement. ${ }^{2,3}$ Although several authors have suggested that preoperative EF and LV end-systolic dimension (LVESD) are important predictors of postoperative $\mathrm{EF}$, there is also debate about the timing of operation to optimize long-term EF recovery. ${ }^{3-5}$

We sought to determine the clinical and echocardiographic predictors of long-term recovery of normal LVEF after surgical correction of isolated MR caused by leaflet prolapse.

\footnotetext{
From the Divisions of Cardiovascular Surgery ${ }^{\mathrm{a}}$ and Cardiovascular Diseases, ${ }^{\mathrm{b}}$ Mayo Clinic, Rochester, Minn.

Conflicts of interest: Drs Suri, Schaff, Dearani, Daly, Mullany, and Orszulak have no conflicts of interest with this manuscript. Dr Sundt has stated consultant/advisory board: Boston Scientific Advisory Board. Dr Enriquez-Sarano has stated research grants: Edwards Lifesciences, AstraZeneca, and Pfizer; honoraria: Edwards Lifesciences; and consultant/advisory board: Edwards Lifesciences.

Received for publication March 6, 2008; revisions received Aug 13, 2008; accepted for publication Oct 26, 2008.

Address for reprints: Rakesh M. Suri, MD, DPhil, Division of Cardiovascular Surgery, Mayo Clinic, 200 First St SW, Rochester, MN 55905 (E-mail: suri.rakesh@mayo. $\mathrm{edu})$.

J Thorac Cardiovasc Surg 2009;137:1071-6

$0022-5223 / \$ 36.00$

Copyright (C) 2009 by The American Association for Thoracic Surgery

doi:10.1016/j.jtcvs.2008.10.026
}

\section{PATIENTS AND METHODS}

This study was a retrospective review of the medical records of patients undergoing primary surgical correction (repair or replacement) of MV insufficiency resulting from leaflet prolapse. The study was approved by the Mayo Clinic Institutional Review Board. All patients in this study had preoperative echocardiography plus a follow-up echocardiographic assessment of LVEF. We excluded patients who declined involvement in clinical research, had previous MV surgery or concomitant cardiac procedures, or had a primary diagnosis of MR caused by congenital or ischemic heart disease or other forms of cardiomyopathy. Also excluded were patients with endocarditis causing leaflet defects or subvalvular abscess at the time of the primary MV repair. We included patients who had concomitant coronary artery bypass graft surgery or closure of a secundum atrial septal defect or patent foramen ovale.

Between January 1, 1980, and December 31, 1999, a total of 2219 patients underwent surgical correction of MR at Mayo Clinic in Rochester, Minnesota. Of these patients, 1063 with MR resulting from leaflet prolapse met the study's selection criteria; 924 had MV repair and 139 had MV replacement. There were 79 mechanical valves implanted (Björk-Shiley [Shiley, Irvine, Calif], 3; CarboMedics [Sulzer CarboMedics, Austin, Tex], 6; St Jude Medical [St. Paul, Minn], 24; Starr-Edwards [Edwards Lifesciences, Irvine, Calif], 46), and 60 patients had biological prostheses (Carpentier-Edwards [Edwards Lifesciences], 44; Hancock [Medtronic, Minneapolis, Minn], 8; Ionescu-Shiley [Shiley], 8). A total of 2488 follow-up echocardiograms were included in the analysis. They were performed at a mean $( \pm \mathrm{SD})$ of $2.9 \pm 3.9$ years postoperatively (predismissal, $914 ; \leq 1$ year, $244 ; 1-3$ years, $233 ; 3-5$ years, 217 ). EF in our laboratory is measured by a combination of visually estimated EF using 2-dimensional echocardiography ${ }^{6,7}$ and a calculation based on M-mode diameters obtained under guidance with 2-dimensional echocardiography. ${ }^{8}$

\section{Surgical Procedure}

Indications for operation and surgical techniques evolved over the 20year study period. During the second decade of the study, we used a strategy 


$$
\begin{aligned}
& \text { Abbreviations and Acronyms } \\
& \begin{aligned}
\mathrm{EF} & =\text { ejection fraction } \\
\mathrm{HR} & =\text { hazard ratio } \\
\mathrm{LV} & =\text { left ventricular } \\
\mathrm{LVEDD} & =\text { left ventricular end-diastolic dimension } \\
\mathrm{LVEF} & =\text { left ventricular ejection fraction } \\
\mathrm{LVESD} & =\text { left ventricular end-systolic dimension } \\
\mathrm{MR} & =\text { mitral regurgitation } \\
\mathrm{MV} \quad & =\text { mitral valve }
\end{aligned}
\end{aligned}
$$

\begin{tabular}{|c|c|c|c|}
\hline Variable & $\begin{array}{c}\text { Repair } \\
(n=924)\end{array}$ & $\begin{array}{c}\text { Replacement } \\
(\mathbf{n}=139)\end{array}$ & $\begin{array}{c}P \\
\text { value }\end{array}$ \\
\hline Age, $y$ & 62.4 & 67.4 & $<.001$ \\
\hline Sex & & & .36 \\
\hline Male & $666(72)$ & $95(68)$ & \\
\hline Female & $258(28)$ & $44(32)$ & \\
\hline Preoperative AF & $95(10)$ & $24(17)$ & .02 \\
\hline NYHA class & & & $<.001$ \\
\hline I & $125(14)$ & $5(4)$ & \\
\hline II & $242(26)$ & $17(12)$ & \\
\hline III & $480(52)$ & $88(63)$ & \\
\hline IV & $77(8)$ & $29(21)$ & \\
\hline Decade of surgery (1990s vs 1980s) & $814(88)$ & $85(61)$ & $<.001$ \\
\hline Preoperative MI & $75(8)$ & $35(25)$ & $<.001$ \\
\hline CABG & $232(25)$ & $51(37)$ & .004 \\
\hline Preoperative EF, \% & 62 & 59 & $<.001$ \\
\hline Preoperative LVEDD, mm & 60 & 61 & .71 \\
\hline Preoperative LVESD, mm & 37 & 39 & .12 \\
\hline Preoperative left atrial size, $\mathrm{mm}$ & 52 & 55 & .02 \\
\hline Predischarge MR $\ddagger$ & & & $<.001$ \\
\hline None & 348 (38) & $83(64)$ & \\
\hline Trivial & $361(40)$ & $37(28)$ & \\
\hline Mild & 155 (17) & $9(7)$ & \\
\hline Moderate & $38(4)$ & $1(1)$ & \\
\hline Severe & $7(1)$ & $0(0)$ & \\
\hline
\end{tabular}

TABLE 1. Baseline characteristics of patients*†

of earlier MV repair for MR resulting from leaflet prolapse on the basis of quantitative echocardiographic criteria. ${ }^{9}$ The most frequent lesion overall for which patients underwent surgical correction of MR at Mayo Clinic was isolated posterior leaflet prolapse of the middle scallop, caused by either chordal elongation or chordal rupture. The most common repair was triangular resection and suture reconstruction of the involved portion of the posterior leaflet, supplemented by a standard-length $(63 \mathrm{~mm})$ flexible posterior annuloplasty band. ${ }^{10,11}$ During the first decade of the study, anterior leaflet prolapse was corrected by chordal shortening, chordal transfer, or commissuroplasty. In the more recent era (the 1990s), insertion of artificial neochordae (expanded polytetrafluoroethylene; Gore-Tex; W. L. Gore $\&$ Associates, Inc, Flagstaff, Ariz) was used for repair of anterior leaflet prolapse. $^{12}$

Among the 139 patients who underwent MV replacement, 79 (57\%) received a mechanical valve and $60(43 \%)$ received a bioprosthesis. Chordal preservation during valve replacement was documented in 123 patients $(88.5 \%)$.

\section{Statistical Analysis}

Group statistics were expressed as the mean \pm 1 SD. Categorical variables were compared between groups by the $\chi^{2}$ test for independence. A 2-sample $t$ test was used to compare continuous factors between groups. The cumulative probability of $\mathrm{EF}$ recovery $(\mathrm{EF} \geq 60 \%)$ was estimated by the Kaplan-Meier method. Multivariate models to identify potential predictors of this end point were investigated by Cox proportional hazards and were constructed by stepwise selection in 2 stages because of the inability to collect all measurements from each study. The first stage used only clinical variables and preoperative $\mathrm{EF}$ as potential predictors. The second stage analyzed the importance of other echocardiographic variables. To determine importance, we forced each of the second-stage variables into the final clinical model. Optimal preoperative EF and LVESD cut points that were most predictive of an $\mathrm{EF}$ of $60 \%$ or greater during long-term follow-up were identified after adjustment for significant factors in the clinical multivariate model. Overall trends in the $\mathrm{EF}$ at various postoperative time points were compared by generalized estimation equation models.

\section{RESULTS}

\section{Baseline Characteristics}

Baseline characteristics for all 1063 patients who had MV repair or MV replacement are summarized in Table 1. Patients who had MV repair were younger, had a lower incidence of atrial fibrillation, had better functional class by New York Heart Association criteria, less frequently had coronary artery disease or preoperative myocardial infarction, were more likely to have undergone operation in the 1990s, and had greater preoperative EF and smaller left atrial dimensions.
$A F$, Atrial fibrillation; $C A B G$, coronary artery bypass graft; $E F$, ejection fraction; LVEDD, left ventricular end-diastolic dimension; $L V E S D$, left ventricular end-systolic dimension; $M I$, myocardial infarction; $M R$, mitral regurgitation; NYHA, New York Heart Association. $* \mathrm{~N}=1063$. $\uparrow$ Values are number (percentage) unless indicated otherwise. $\ddagger$ For repair, $\mathrm{n}=909$; for replacement, $\mathrm{n}=130$.

\section{Changes in Long-Term Postoperative EF and Ventricular Dimensions}

Echocardiographic data were grouped into the following categories: preoperative, predismissal, 1 year or less, 1 to 3 years, and 3 to 5 years. After an initial decline in mean EF from preoperative to predismissal time points, EF improved steadily (ie, recovered) and significantly to the time of the last follow-up echocardiogram (Figure 1). An early decrease in mean LV end-diastolic dimension (LVEDD) occurred immediately postoperatively and continued thereafter. Mean LVESD did not change appreciably between the adjacent periods; however, there was a significant regression overall in systolic dimension between predismissal echocardiograms and those obtained at 3- to 5-year follow-up.

\section{Predictors of EF Recovery} fied by univariate and multivariate analyses (Table 2). Clinical factors independently associated with recovery of normal function $(\mathrm{EF} \geq 60 \%$ ) during long-term follow-up included MV repair $(P=.03)$, freedom from preoperative myocardial infarction $(P=.02)$, and time of surgery in the 1990s $(P<.001)$. After adjustment for these variables, important preoperative echocardiographic predictors were
Several predictors of long-term EF recovery were identi- 

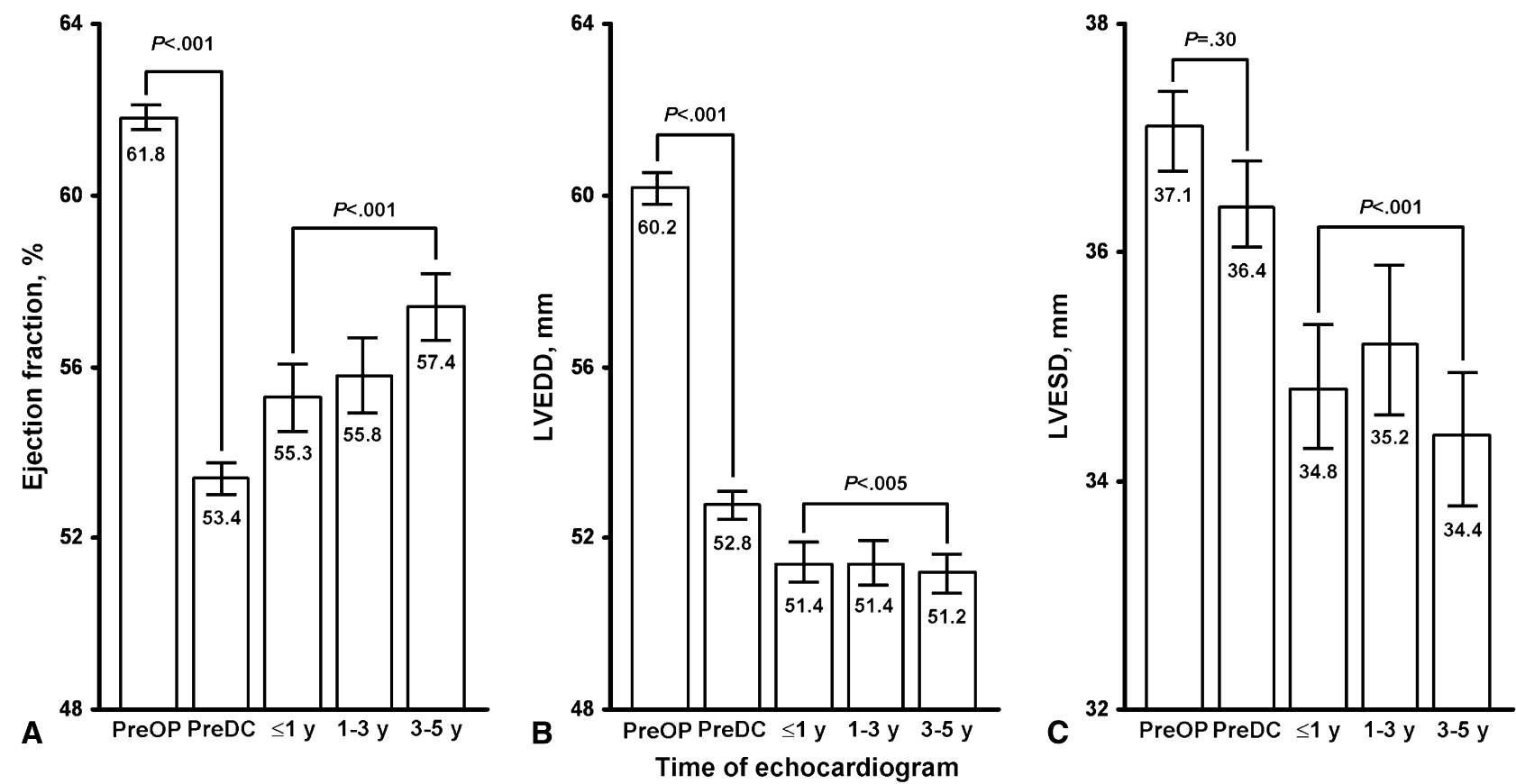

FIGURE 1. Change in mean left ventricular ejection fraction $(E F)$, mean left ventricular end-diastolic dimension (LVEDD), and mean left ventricular end-systolic dimension ( LVESD) between preoperative and last follow-up echocardiograms. A, After an initial decline from the preoperative $($ PreOP) period to the postoperative period, EF improved steadily and significantly with time from the predischarge (PreDC) echocardiogram to the last follow-up echocardiogram. $B$, LVEDD decreased significantly from PreOP to PreDC and continued to decline to last follow-up echocardiogram. $C$, No change in LVESD occurred in the early postoperative period, but significant LVESD regression occurred with time after discharge. The number of patients with grade of mitral regurgitation greater than $3+$ (percent) is 983 (97) for PreOP; 46 (5) for PreDC; 4 (7) for $\leq 1$ year; 9 (16) for 1 to 3 years; and 19(18) for 3 to 5 years. Error bars indicate mean \pm standard error.

identified as greater EF $(P<.001)$ and smaller LV dimensions (LVEDD and LVESD, $P=.001$ ).

\section{Effect of the Decade of Operation}

Clinically significant differences were noted in patients who underwent surgical correction of MR in the 1980s compared with patients who had surgery in the 1990s (Table 3). Patients operated on in the second decade of the study were significantly less symptomatic $(P<.001)$, and they had smaller LV dimensions (LVEDD and LVESD; $P<.001$ ), less atrial fibrillation $(P=.009)$, and shorter crossclamp/ cardiopulmonary bypass times $(P<.001$ for each). They also had a 2.4-fold greater likelihood of normalization of EF during long-term follow-up $(P<.001)$.

\section{Effect of Postoperative LV Dysfunction}

Patients who had MV surgery were categorized on the basis of their predismissal $\mathrm{EF}$ ( $\mathrm{EF} \geq 50 \%$ or $<50 \%$ ) (Figure 2). Patients with postoperative LV dysfunction $(\mathrm{EF}<50 \%)$ had significantly lower EF and were less likely to regain normal EF during long-term follow-up.

\section{Preoperative Thresholds for EF and LVESD Optimization of Long-Term EF Recovery}

To determine the optimal timing of surgical correction of MV regurgitation with respect to recovery of LV function, we sought to identify putative "cut points" for preoperative EF and LVESD that were most predictive of normal EF during long-term follow-up. Using multivariate modeling, we determined that a preoperative $\mathrm{EF}$ of greater than $65 \%$ (hazard ratio $[\mathrm{HR}], 1.8 ; P<.001$ ) (Figure $3, A$ ) and an LVESD of less than $36 \mathrm{~mm}(\mathrm{HR}, 2.0 ; P<.001)$ (Figure $3, B)$ resulted in the greatest likelihood of postoperative recovery of normal $\mathrm{EF}$ (EF $\geq 60 \%$ ). These 2 factors predicted recovery after MV repair $(P<.001$ for each) but not after MV replacement $(P=.31$ and $P=.07$, respectively).

\section{DISCUSSION}

The purpose of this study was to observe the change in LV size and function during long-term echocardiographic follow-up after surgical correction of MR caused by leaflet prolapse and to identify factors predictive of more complete recovery of normal EF. We found that after an initial decline in the early postoperative period, mean EF improved steadily and significantly with time from operation to last follow-up. Clinical predictors of better EF recovery were MV repair (vs MV replacement), operation in the more recent decade, and freedom from preoperative myocardial infarction.

In our previous studies, we have found that EF decreases after correction of MR and to a similar extent whether 
TABLE 2. Univariate and multivariate predictors of EF recovery

\begin{tabular}{|c|c|c|c|c|}
\hline \multirow[b]{2}{*}{ Variable } & \multicolumn{2}{|c|}{ Univariate } & \multicolumn{2}{|c|}{ Multivariate } \\
\hline & HR & $P$ value & HR & $P$ value \\
\hline Age & 1.00 & .39 & NA & NA \\
\hline Female sex & 1.15 & .15 & NA & NA \\
\hline Preoperative AF & 0.79 & .09 & NA & NA \\
\hline NYHA class & 0.88 & .02 & NA & NA \\
\hline Preoperative EF & 1.04 & $<.001$ & 1.04 & $<.001 *$ \\
\hline Preoperative LVEDD & 0.95 & $<.001$ & 0.96 & $<.001 *$ \\
\hline Preoperative LVESD & 0.94 & $<.001$ & 0.94 & $<.001 *$ \\
\hline Preoperative left atrial size & 0.99 & .08 & NA & NA \\
\hline \multicolumn{5}{|l|}{ Prolapse } \\
\hline Anterior leaflet vs posterior leaflet & 0.93 & .65 & NA & NA \\
\hline Bileaflet vs posterior leaflet & 1.08 & .46 & NA & NA \\
\hline Preoperative MI & 0.59 & .002 & 0.67 & .02 \\
\hline CABG & 0.87 & .20 & NA & NA \\
\hline Repair vs replacement & 1.71 & $<.001$ & 1.40 & .03 \\
\hline Decade of surgery (1990s vs 1980s) & 2.39 & $<.001$ & 2.14 & $<.001$ \\
\hline Predischarge MR & 0.93 & .54 & NA & NA \\
\hline \multicolumn{5}{|c|}{$\begin{array}{l}A F \text {, Atrial fibrillation; } C A B G \text {, coronary artery bypass graft; } E F \text {, ejection fraction; } H R \text {, } \\
\text { hazard ratio; } L V E D D \text {, left ventricular end-diastolic dimension; } L V E S D \text {, left ventricular } \\
\text { end-systolic dimension; } M I \text {, myocardial infarction; } M R \text {, mitral regurgitation; } N A \text {, not } \\
\text { applicable; } N Y H A \text {, New York Heart Association. *Model includes echocardiographic } \\
\text { variables after adjustment for significant clinical factors (ie, preoperative myocardial } \\
\text { infarction, type of surgery, and decade of surgery); not all parameters are in model } \\
\text { simultaneously. }\end{array}$} \\
\hline
\end{tabular}

patients had valve repair or replacement. In the current study, however, we found that the long-term recovery of EF was better after valve repair. This novel finding supports existing evidence in the medical literature that patients with degenerative MV disease accrue greater benefit from MV repair than from MV replacement. Several other authors who have examined LV function in the early perioperative period have arrived at various conclusions about the equivalence of repair versus replacement for preservation of normal EF. ${ }^{5,13-16}$ There has also been debate about the importance of chordal preservation during MV replacement. ${ }^{17-19}$ Our study examined a cohort of patients who had MV replacement with a high frequency $(88.5 \%)$ of chordal preservation, yet MV repair remained an independent predictor of

TABLE 3. Preoperative risk profile by decade of operation

\begin{tabular}{lccc}
\hline \multicolumn{1}{c}{ Variable } & 1980s & 1990s & $\boldsymbol{P}$ value \\
\hline NYHA classes I-II, \% & 15 & 40 & $<.001$ \\
Preoperative LVEDD, mm & 64 & 59 & $<.001$ \\
Preoperative LVESD, mm & 39 & 36 & $<.001$ \\
Preoperative AF, \% & 17 & 10 & .009 \\
Crossclamp time, min & 61 & 49 & $<.001$ \\
CPB time, min & 92 & 72 & $<.001$ \\
Age, y & 65 & 63 & .24 \\
Male sex, \% & 70 & 72 & .52 \\
\hline
\end{tabular}

$A F$, Atrial fibrillation; $C P B$, cardiopulmonary bypass; $L V E D D$, left ventricular enddiastolic dimension; LVESD, left ventricular end-systolic dimension; NYHA, New York Heart Association.

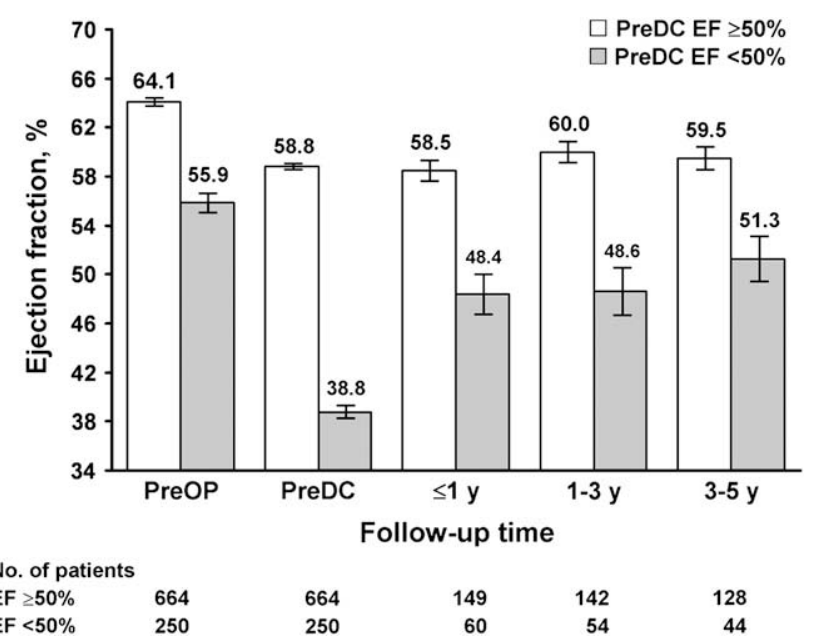

FIGURE 2. The effects of postoperative left ventricular dysfunction were evaluated by examining long-term recovery of left ventricular ejection fraction $(E F)$. Patients who underwent mitral valve surgery were categorized into 2 groups on the basis of their predischarge (PreDC) EF and were evaluated at follow-up ( $\leq 1$ year, 1-3 years, and 3-5 years) for long-term recovery of ventricular function. Patient numbers at each time period are noted. Error bars indicate mean \pm standard error. PreOP, Preoperative.

superior LVEF during long-term follow-up, which indicates that the mechanism of benefit after valve repair is likely more complex than the mere maintenance of ventriculovalvular continuity.

The identification of predictors of recovery of normal EF is important because the prognosis associated with LV dysfunction after surgery is poor. ${ }^{4}$ The finding in this study that postoperative LV dysfunction is also a predictor of inferior long-term recovery of LV function (Figure 2) is perhaps etiologic. Although predictors of normalization of ventricular function during the early postoperative period have been described previously, ${ }^{4,20}$ the current study is different in that it analyzed a large and homogeneous population of patients with MR caused by leaflet prolapse in the absence of confounding factors such as other pathologic valve conditions or cardiomyopathy. Our conclusions are likely generalizable to patients with isolated degenerative MV disease.

Our data showed that less symptomatic patients are more likely to have superior recovery of EF during long-term follow-up, which may explain the findings of prior reports suggesting that survival is improved in patients with better preoperative New York Heart Association functional class. ${ }^{9,21,22}$ Other investigators also have suggested that significant coronary artery disease and preoperative myocardial infarction are risk factors for diminished LV function after MV surgery. ${ }^{4}$ Although operative and pathologic reports for patients in our study showed that MR was primarily due to degenerative leaflet prolapse, we cannot exclude the possibility of ischemic disease, the presence of which may partially explain this finding. 
Operative criteria and surgical techniques evolved over the study period, and an attempt was made to identify these differences on the basis of the decade of operation (Table 3). Patients operated on in the 1990s were less symptomatic and had a decreased incidence of atrial fibrillation, had smaller LV dimensions, and had shorter operative times. These factors are associated with a more favorable clinical profile, which may be related to surgical correction performed earlier in the disease course. However, patients operated on in the second decade of the study also had improved normalization of postoperative $\mathrm{EF}$, even after we controlled for these factors in our multivariate analysis. The superior late EF in this population is likely reflective of the favorable clinical and physiologic attributes of patients sent for an earlier MV operation in general.

We determined that the most influential thresholds for recovery of normal EF during long-term follow-up were a preoperative EF greater than $65 \%$ and an LVESD less than 36 $\mathrm{mm}$. These values are the most advanced indications for mitral operation that have been identified to date. It is important to remember that these results were obtained under a programatic policy of performing mitral repair for severe MR before the development of LV dysfunction. Authors of at least two other studies have suggested that greater preoperative EF and smaller LVESD predict improved ventricular function after surgical correction of MR. ${ }^{4,20}$ An earlier report from our institution examining patient survival recommended that operative intervention be performed before EF deterioration to less than $60 \%$ or LVESD dilatation to more than $45 \mathrm{~mm} .{ }^{4}$ A more recent study by Matsumura and associates ${ }^{20}$ indicated that a preoperative EF less than $55 \%$ and an LVESD greater than $40 \mathrm{~mm}$ both predicted an increased incidence of postoperative LV dysfunction. Our objective was slightly different: to identify the predictors of long-term recovery of normal EF after MV repair compared with MV replacement. Importantly, we found that the benefit of early operation is recognized only in patients undergoing MV repair but not in those having MV replacement. Delaying operation until the development of ventricular dilatation or dysfunction and denying patients access to MV repair are clearly antagonistic to the goal of postoperative normalization of $\mathrm{LV}$ function.

\section{Limitations}

This study was a retrospective review and thus is influenced by the traditional limitations. We were unable to obtain equivalent numbers and timing of follow-up echocardiograms for all the patients in our study over the 2 decades it encompassed. Patients with more frequent echocardiographic assessments may have been observed more closely because of some distinguishing clinical feature, and those with poor postoperative EF who did not survive after discharge are obviously not included in the long-term analysis. Finally, we reviewed clinical records and patient
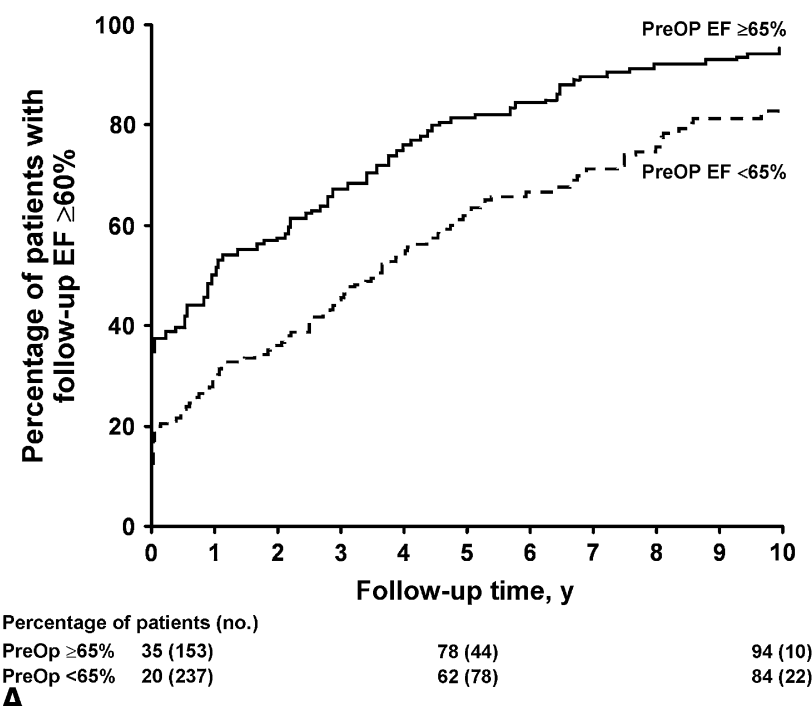
PreOp $<65 \% \quad 20(237)$

A

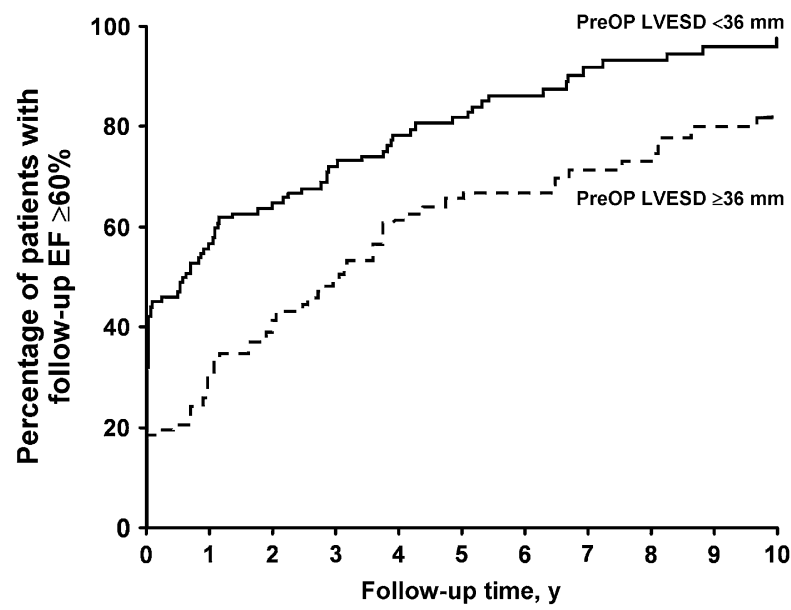

Percentage of patients (no.)

PreOp $\geq 65 \% \quad 35(153)$

PreOp $<65 \% \quad 20(237)$

78 (44)

$94(10)$

B

FIGURE 3. Predictors of recovery of left ventricular ejection fraction $(E F)$ during follow-up detailed through Kaplan-Meier plots delineating the percentage of patients who reattained normal left ventricular $\mathrm{EF}(\mathrm{EF} \geq 60 \%)$ over time after mitral value surgery. $A$, Recovery of normal EF stratified by preoperative (PreOP) EF (EF $\geq 65 \%$ or $<65 \%$ ). B, Recovery of normal EF stratified by PreOP left ventricular end-systolic dimension (LVESD) (LVESD $\geq 36 \mathrm{~mm}$ or $<36 \mathrm{~mm}$ ).

correspondence and conducted surveys to record the most up-to-date clinical and echocardiographic information; however, follow-up data in a study as large as this one are admittedly heterogeneous.

\section{Clinical Implications}

Our findings underline the recommendation that MV repair is preferable in patients undergoing surgical correction of MV regurgitation caused by degenerative leaflet prolapse. The assumption that MV surgery can be delayed until symptom onset, a decline in EF, or LV dilatation is incorrect and 
may be deleterious to the health of patients. Patients with postoperative LV dysfunction are at high risk for depressed long-term EF. Consideration for MV repair should be undertaken early for patients with severe MR.

\section{CONCLUSIONS}

Normalization of EF and reverse remodeling of LV dimensions are possible after surgical correction of degenerative MR. Better outcomes were observed in patients undergoing operation for severe MR with preserved LV function $(E F>65 \%)$ and smaller left heart dimensions (LVESD $<36 \mathrm{~mm}$ ). These data should prompt the re-evaluation of guidelines, to recommend earlier MV surgery in the presence of significant MR for optimal recovery of normal EF. Withholding surgery from patients while allowing MR to persist increases the risk of irreversible impairment in long-term LV function.

\section{References}

1. Starling MR, Kirsh MM, Montgomery DG, Gross MD. Impaired left ventricular contractile function in patients with long-term mitral regurgitation and normal ejection fraction. J Am Coll Cardiol. 1993;22:239-50.

2. Starling MR. Effects of valve surgery on left ventricular contractile function in patients with long-term mitral regurgitation. Circulation. 1995;92:811-8.

3. Flemming MA, Oral H, Rothman ED, Briesmiester K, Petrusha JA, Starling MR. Echocardiographic markers for mitral valve surgery to preserve left ventricular performance in mitral regurgitation. Am Heart J. 2000; 140:476-82.

4. Enriquez-Sarano M, Tajik AJ, Schaff HV, Orszulak TA, McGoon MD, Bailey KR, et al. Echocardiographic prediction of left ventricular function after correction of mitral regurgitation: results and clinical implications. J Am Coll Cardiol. 1994;24:1536-43.

5. Le Tourneau T, de Groote P, Millaire A, Foucher C, Savoye C, Pigny P, et al. Effect of mitral valve surgery on exercise capacity, ventricular ejection fraction and neurohormonal activation in patients with severe mitral regurgitation. $J$ Am Coll Cardiol. 2000;36:2263-9.

6. Rich S, Sheikh A, Gallastegui J, Kondos GT, Mason T, Lam W. Determination of left ventricular ejection fraction by visual estimation during real-time two-dimensional echocardiography. Am Heart J. 1982;104:603-6.

7. Amico AF, Lichtenberg GS, Reisner SA, Stone CK, Schwartz RG, Meltzer RS. Superiority of visual versus computerized echocardiographic estimation of radionuclide left ventricular ejection fraction. Am Heart J. 1989;118:1259-65.
8. Quinones MA, Waggoner AD, Reduto LA, Nelson JG, Young JB, Winters WL Jr, et al. A new, simplified and accurate method for determining ejection fraction with two-dimensional echocardiography. Circulation. 1981;64:744-53.

9. Enriquez-Sarano M, Avierinos JF, Messika-Zeitoun D, Detaint D, Capps M, Nkomo V, et al. Quantitative determinants of the outcome of asymptomatic mitral regurgitation. $N$ Engl J Med. 2005;352:875-83.

10. Suri RM, Orszulak TA. Triangular resection for repair of mitral regurgitation due to degenerative disease. Oper Tech Thorac Cardiovasc Surg. 2005;10:194-9.

11. Seccombe JF, Schaff HV. Mitral valve repair: current techniques and indications. In: Franco KL, Verrier ED, eds. Advanced therapy in cardiac surgery. Hamilton (Ont): B.C. Decker; 1999. p. 220-31

12. Phillips MR, Daly RC, Schaff HV, Dearani JA, Mullany CJ, Orszulak TA. Repair of anterior leaflet mitral valve prolapse: chordal replacement versus chordal shortening. Ann Thorac Surg. 2000;69:25-9.

13. Bonchek LI, Olinger GN, Siegel R, Tresch DD, Keelan MH Jr. Left ventricular performance after mitral reconstruction for mitral regurgitation. J Thorac Cardiovasc Surg. 1984;88:122-7.

14. Goldman ME, Mora F, Guarino T, Fuster V, Mindich BP. Mitral valvuloplasty is superior to valve replacement for preservation of left ventricular function: an intraoperative two-dimensional echocardiographic study. J Am Coll Cardiol. 1987;10: 568-75.

15. Ren JF, Aksut S, Lighty GW Jr, Vigilante GJ, Sink JD, Segal BL, et al. Mitral valve repair is superior to valve replacement for the early preservation of cardiac function: relation of ventricular geometry to function. Am Heart J. 1996;131: 974-81.

16. Corin WJ, Sutsch G, Murakami T, Krogmann ON, Turina M, Hess OM. Left ventricular function in chronic mitral regurgitation: preoperative and postoperative comparison. J Am Coll Cardiol. 1995;25:113-21.

17. David TE, Burns RJ, Bacchus CM, Druck MN. Mitral valve replacement for mitral regurgitation with and without preservation of chordae tendineae. $J$ Thorac Cardiovasc Surg. 1984;88:718-25.

18. Lillehei CW, Levy MJ, Bonnabeau RC Jr. Mitral valve replacement with preservation of papillary muscles and chordae tendineae. J Thorac Cardiovasc Surg. 1964;47:532-43.

19. Rastelli GC, Tsakiris AG, Frye RL, Kirklin JW. Exercise tolerance and hemodynamic studies after replacement of canine mitral valve with and without preservation of chordae tendineae. Circulation. 1967;35(4 Suppl):I34-41.

20. Matsumura T, Ohtaki E, Tanaka K, Misu K, Tobaru T, Asano R, et al. Echocardiographic prediction of left ventricular dysfunction after mitral valve repair for mitral regurgitation as an indicator to decide the optimal timing of repair. $J A m$ Coll Cardiol. 2003;42:458-63.

21. David TE, Ivanov J, Armstrong S, Rakowski H. Late outcomes of mitral valve repair for floppy valves: implications for asymptomatic patients. $J$ Thorac Cardiovasc Surg. 2003;125:1143-52.

22. Mohty D, Orszulak TA, Schaff HV, Avierinos JF, Tajik AJ, Enriquez-Sarano M. Very long-term survival and durability of mitral valve repair for mitral valve prolapse. Circulation. 2001;104(12 Suppl 1)1:I1-7. 